\title{
EFECTO DEL FOSFORO SOBRE LA POBLACION MICROBIANA EN SUELOS CON PASTURAS EN LA ZONA ALTOANDINA DE JUNIN \\ Doris Pahuara Hernandez ${ }^{1}$ y Doris Zúñiga Dávila²
}

\section{Resumen}

Se evaluó el efecto de la fertilización fosforada $\left(80 \mathrm{Kg}_{2} \mathrm{O}_{5} / \mathrm{ha}\right)$ sobre la población microbiana del suelo y la producción de materia seca en la pastura asociada Rye-grass/trébol (Lolium perenne / Trifolium repens y Trifolium pratense) en zona altoandina del Perú.

Se encontró que la población de bacterias mesófilas, hongos, Rhizobium y Azotobacter fueron mayores en el tratamiento con fósforo en comparación con el tratamiento sin fósforo. Las más bajas poblaciones de todos los microorganismos en estudio se observaron en los meses de Mayo y Julio, meses en los que se registraron las temperaturas del suelo más bajas, y las poblaciones más altas en los meses de Enero y Noviembre.

Los pesos secos (PST, PS trébol, PS rye-grass) fueron significativamente mayores en el tratamiento con fósforo. Además se observó que el trébol respondió mejor a la fertilización que el Rye-grass. Los más altos rendimientos de materia seca del trébol y rye-grass corresponden a las más altas poblaciones de Rhizobium y Azotobacter respectivamente. Esto sugiere que la fijación biológica del $\mathrm{N}_{2}$ favorece el crecimiento de la pastura.

Palabras claves: Rizósfera, Rhizobium, Azotobacter, trébol, fósforo.

\begin{abstract}
A study was conducted to investigate the phosphorus fertilization effect $\left(80 \mathrm{Kg} \mathrm{P}_{2} \mathrm{O}_{5} / \mathrm{ha}\right)$ on the microbial population and the total dry matter weight (DW) of Rye-grass/Clover associated pasture (Lolium perenne / Trifolium repens and Trifolium pratense) in highlands of Peru.

The results showed that mezophile bacteria, fungi, Rhizobium y Azotobacter populations were higher in the phosphorus treatment compared with the non-phosphorus treatment. The lowest microbial population levels were between May and July. These months registered the lowest soil temperatures. The highest microbial population levels were obtained in January and November The dry matter weight (total WD, Clover WD, Rye-grass WD) were highly significant in the phosphorous treatment. Moreover, better fertilization answers were established for Clover than for Rye-grass. The highest yields of Clover and Rye-grass dry matter weight have a positive correlation with the highest Rhizobium - Azotobacter populations respectively. This suggests that nitrogen biological fixation improve the growth of the pasture.
\end{abstract}

Key words : Rhizosphere, Rhizobium, Azotobacter, clover, phosphorous.

\section{Introducción}

En el Perú, actualmente, el $49 \%$ de la superficie agrícola pertenece a pastos cultivados y naturales, destinados principalmente para alimento de ganado y ubicados en su mayoría en la región altoandina peruana que alberga al $78,8 \%$ del ganado vacuno (Ministerio de Agricultura, 1994). Sin embargo, los suelos de esta zona son pobres en nitrógeno, fósforo y en general de baja fertilidad, lo que incide en la productividad de los suelos, por lo tanto, limita la producción. Numerosas investigaciones sobre los niveles críticos de fósforo en suelos de sierra consideran rangos: bajo (0-6 ppm), medio (7-15 ppm) y altos (15 ppm a más) (Flores y Bryant, 1989). De

Las leguminosas requieren relativamente grandes cantidades de fósforo para su óptimo desarrollo, a su vez este elemento tiene una influencia sobre la fijación simbiótica del nitrógeno, ya que al estimular el crecimiento radicular de las plantas favorece la acuerdo a esta clasificación, la literatura recomienda dosis de $100, \quad 80 \quad$ y $\quad 60 \quad \mathrm{Kg} \quad \mathrm{P}_{2} \mathrm{O}_{5} \quad$ /ha/año respectivamente (Flores y Malpartida, 1987). Sin embargo, la fertilización fosforada para el mantenimiento de pasturas asociadas no está adecuadamente manejado. Esto es de particular importancia en suelos de pasturas asociadas con leguminosas, donde las bacterias fijadoras de nitrógeno deben ser eficientes, es decir, lograr una alta tasa de fijación de nitrógeno atmosférico, lo que tendrá como consecuencia un forraje de mayor calidad nutritiva, mayores rendimientos de materia seca y una mayor fertilidad del suelo nodulación e incrementa el número y peso de los nódulos. Si bien la penetración de Rhizobium es posible a bajos niveles de fósforo las infecciones posteriores no se realizan en estas condiciones (Escobedo, 1993). Además, el requerimiento de ATP

\footnotetext{
${ }^{12}$ Laboratorio de Ecología Microbiana Y Biotecnología "Marino Tabusso" del Departamento de Biología. Universidad Nacional Agraria La Molina, Apartado Postal 456, Lima 1, Perú. Email: dzuniga@lamolina.edu.pe
} 
para la fijación de nitrógeno es muy alto, en la reacción global se requieren 18 ATPs, para bajar el potencial de reducción de la nitrogenasa lo suficiente de modo que el $\mathrm{N}_{2}$ se pueda reducir a $\mathrm{NH}_{3}$ (Sylvia et. al., 1998).

Buckman y Brady (1993) indican que el nitrógeno fijado por la leguminosa puede ser usado por ella misma o pasar al suelo. De allí que las gramíneas sembradas y asociadas con leguminosas pueden aprovechar el nitrógeno favorablemente incrementando su crecimiento y desarrollo. La cantidad de nitrógeno fijado está en relación con el tipo de leguminosa, variando de 56 a $323 \mathrm{Kg}$. de nitrógeno/ha/año (Escobedo, 1993). Por otro lado, Vigo (1971) reportó que con abonamiento fosforado y un buen manejo de la asociación Rye-grass/trébol se puede obtener hasta $35000 \mathrm{Kg}$ follaje verde(MV)/corte y $175000 \mathrm{Kg} / \mathrm{ha} / \mathrm{año}$. Por lo tanto, un manejo sostenido de estas zonas de pastizales beneficiaría significativamente la producción ganadera.

Son pocos los estudios realizados en el Perú respecto a leguminosas forrajeras y su simbiosis con rizobios (Escobedo, 1993), en comparación a leguminosas de grano como frejol y pallar (MatosCuzcano et al., 1998; Ormeño y Zúñiga, 1998; Zúñiga, 1997; Camarena et al.,1990).

El objetivo de este estudio fue el de evaluar el efecto de la fertilización fosforada sobre la población microbiana del suelo y la producción de materia seca en pastos asociados en zonas alto andinas del Perú.

\section{Materiales y métodos}

\section{Lugar experimental}

El trabajo se realizó en la Unidad de Producción Pachacayo de la Sociedad Agrícola de Interés Social "Tupac Amaru" Ltda., ubicada en el distrito de Canchayllo, provincia de Jauja, departamento de Junín a 3600 m.s.n.m en un módulo de aproximadamente 19 ha. de pastos cultivados, establecidos hace 30 años. La pastura es una asociación de: Rye-grass - Trébol (Lolium perenne Trifolium repens y Trifolium pratense), dedicadas principalmente al pastoreo de ganado vacuno para producción lechera (ONERN, 1976). El suelo es de textura franca con un $\mathrm{pH}$ de 7,3, materia orgánica de 2,6\%, $609 \mathrm{Kg} \mathrm{K}_{2} \mathrm{O} /$ ha y 11,4 ppm de fósforo, la precipitación del año 1999 varió de 0 a $550.4 \mathrm{~mm} / \mathrm{mes}$ y la temperatura ambiental de $-3,47^{\circ}$ a $19,97{ }^{\circ} \mathrm{C}$ (invierno y verano septentrional respectivamente).

Área experimental

El área experimental constó de cuatro potreros de una hectárea en promedio cada uno, dentro de los cuales se cercó un área de $20 \mathrm{~m}$. de ancho x $10 \mathrm{~m}$ de largo (clausura), dividida en dos parcelas iguales de $10 \mathrm{~m} \times 10 \mathrm{~m}$.

\section{Tratamientos}

La fertilización se realizó en el mes de Noviembre de 1998, al inicio de la época de lluvias. La aplicación fue al voleo. Se aplicó $80 \mathrm{Kg} / \mathrm{ha}$ de $\mathrm{P}_{2} \mathrm{O}_{5}$ (Superfosfato Triple) al tratamiento con fósforo, y no se aplicó ningún fertilizante al tratamiento sin fósforo.

Muestreos y toma de muestras

El estudio fue realizado durante el año de 1999. Se realizaron seis muestreos cada dos meses y se tomaron 16 muestras de suelo y follaje.

Las muestras de suelo fueron de $10 \mathrm{~cm}$ de largo por $10 \mathrm{~cm}$ de ancho y $15 \mathrm{~cm}$ de profundidad, con dos repeticiones para cada parcela. La toma de muestra fue con pala, la que se desinfectó previamente con alcohol. Las muestras fueron colocadas en bolsas de plástico, rotuladas y transportadas al laboratorio para su procesamiento antes de las 48 horas de haber sido obtenida

Evaluaciones en el suelo

Se evaluó el porcentaje de humedad y $\mathrm{pH}$ del suelo. El porcentaje de humedad se expresa gravimétricamente:

$\% \mathrm{Hd}=($ Suelo húmedo - Suelo seco)/ Suelo seco $\times 100$

El peso del suelo seco se obtiene llevando el suelo húmedo a estufa a $105^{\circ} \mathrm{C}$ por 24 horas.

El pH del suelo se determinó por el método potenciométrico, en una suspensión de suelo en agua en la proporción de 1:2 respectivamente (UNALM, 1998).

La temperatura del suelo se midió a $10 \mathrm{~cm}$. y 20 $\mathrm{cm}$. de profundidad, introduciendo el bulbo del termómetro hasta la profundidad deseada, la lectura se hizo después de 5 minutos (Gavande, 1979).

Corte y muestreo del follaje

Un mes antes de cada muestreo se cortó el follaje (tiempo cero), a nivel del suelo, con un cuadrante de $0.25 \mathrm{~m}^{2}$, de tal modo que las muestras tomadas correspondieron a un mes de crecimiento del pasto. Este follaje fue embolsado, rotulado, pesado (peso fresco, PF) y transportado al laboratorio para su procesamiento. La materia seca del follaje se obtuvo llevando a estufa a $70^{\circ} \mathrm{C}$ por 48 horas hasta peso constante (peso seco total de la parte aérea - PSTPA, peso seco de la parte aérea de trébol - PSPAt y el peso seco de la parte aérea de Rye -grass - PSPArg).

Infección de plantas estériles de trébol en tubos

Las semillas de trébol fueron esterilizadas en una solución de Hipoclorito de Sodio al 3\% por 3 minutos, luego se lavaron cinco veces con agua estéril y se dejaron en imbibición por una hora. Posteriormente, las semillas fueron trasplantadas asépticamente a placas petri con papel de filtro estéril y se incubaron por 72 horas a $24^{\circ} \mathrm{C}$ en oscuridad hasta su germinación. Las semillas fueron transplantadas a un tubo de ensayo de $20 \times 180 \mathrm{~mm}$ con un soporte de papel de filtro y solución nutritiva de Rigaud y Puppo (tres semillas por tubo), y llevados a la cámara de plantas con 12 horas de luz y 12 horas de oscuridad y 
temperatura de $18^{\circ}$ a $22^{\circ} \mathrm{C}$ durante cinco semanas (CIAT, 1987).

Evaluaciones en la rizósfera

Se cuantificaron poblaciones de Azotobacter y Rhizobium según los métodos citados respectivamente por Burges (1960) y Somasegaran \& Hoben (1985), ambos expresados en NMP/gramo de suelo, así mismo las bacterias mesófilas viables y hongos totales según los métodos citados por Krieg \& Dobereiner (1984) y Merk (1994) respectivamente, ambos expresados en ufc/ gramo de suelo.

Para todas las diluciones se tomaron $10 \mathrm{~g}$ de suelo y se agregaron a un matraz con $90 \mathrm{~mL}$ de solución salina al $0,85 \%$ agitándose vigorosamente por dos minutos (dilución $10^{-1}$ ), con un pipetor estéril se tomó $1 \mathrm{~mL}$ de la suspensión y se llevó a un tubo con $9 \mathrm{~mL}$ de solución salina al $0,85 \%$ (dilución $10^{-2}$ ) y así sucesivamente hasta llegar a la dilución $10^{-5}$.

Para la cuantificación de rizobios se tomaron de las cuatro últimas diluciones, alícuotas de $1 \mathrm{~mL}$ cada una para cuatro tubos que contenían plantas de trébol blanco (Trifolium repens) de una semana de crecimiento, las plantas fueron llevadas a la cámara de plantas según el punto siete. Luego de cuatro semanas se evaluó la presencia o ausencia de nódulos en la raíz y utilizando la tabla de Número más Probable (NMP) se cuantificó la población (Somasegaran \& Hoben, 1985).

Para determinar la población de Azotobacter se tomaron de las cuatro últimas diluciones, alícuotas de $1 \mathrm{~mL}$ cada una para tres tubos con medio específico para Azotobacter (Burges, 1960). Los tubos fueron incubados a $30^{\circ} \mathrm{C}$ por 7 a 10 días. La lectura consistió en la observación de turbidez del medio o la formación de una película en la superficie. El número de bacterias se determinó con la tabla de Mc Grady de NMP (Krieg \& Dobereiner, 1984).

Para el recuento de bacterias mesófilas viables y hongos totales se tomaron de las tres últimas diluciones, alícuotas de $1 \mathrm{~mL}$ cada una para dos placas Petri estériles a las que se les incorporó el medio de cultivo Thorton's y Czapek respectivamente, las placas se incubaron a $28^{\circ} \mathrm{C}$ por 3 a 5 días para bacterias y a $22^{\circ} \mathrm{C}$ por 5 a 7 días para hongos.

Análisis estadístico

Se utilizó un Diseño de Bloques Completo al Azar con Subunidades, con cuatro bloques (clausuras $\mathrm{C} 1$, $\mathrm{C} 2, \mathrm{C} 3, \mathrm{C} 4)$, dos tratamientos (+P, $-\mathrm{P})$ y dos unidades. Se realizó un Análisis de Variancia (ANVA) para materia seca del follaje, y una correlación múltiple entre todas las variables en estudio.

\section{Resultados y discusión}

El efecto del fósforo sobre la población microbiana fue estudiado en base a la cuantificación de cada género y/o grupo en estudio y su comparación con los tratamientos con fósforo y sin fósforo.
En la rizósfera se encontró que las poblaciones de bacterias mesófilas osciló de $10^{5}$ a $10^{7} \mathrm{ufc} / \mathrm{g}$ ss y la población de hongos de $10^{4}$ a $10^{6} \mathrm{ufc} / \mathrm{g}$ ss, estas poblaciones están dentro de los rangos descritos en la literatura (Sylvia et. al., 1998; Alexander, 1994). En tales condiciones, podrían realizar mayores transformaciones de elementos químicos del suelo como mineralización, inmovilización de minerales y solubilización de fosfatos; favorecer el desarrollo de la planta produciendo sustancias estimulantes del crecimiento y contribuyendo a una estructura estable del suelo (Sylvia et. al., 1998; Alexander, 1994).

Generalmente todas las poblaciones microbianas fueron mayores en los tratamientos fertilizados con fósforo que en los no fertilizados durante todo el año. La población de bacterias mesófilas y hongos totales fueron altas en el primer y último muestreo (Figuras 1a y 1b), lo que corresponde a los meses de Enero y Noviembre respectivamente o inicio de la época de lluvias de la región (Figura 2). Así mismo, en las Figuras la y b se observa que la poblaciones disminuye a través del tiempo (Marzo a Setiembre), lo que coincide con la disminución de la temperatura del suelo (Figura 3). Sin embargo, se puede apreciar que las bacterias fueron afectadas drásticamente desde el segundo muestreo, mostrando una mayor sensibilidad a la disminución de la temperatura del suelo que la población de hongos.

Por otro lado, las bacterias fijadoras de nitrógeno de vida libre (Azotobacter) y simbióticas (Rhizobium) también presentaron mayores poblaciones en el tratamiento con fósforo (Figuras 1c y d) aunque esta diferencia se hace menos notoria en la población de Azotobacter. Zúñiga y Gutiérrez-Correa (1982) también encontraron que altas poblaciones de diazótrofos libres (Azotobacter) no correspondían a niveles altos de fósforo (49.8 ppm), pero a niveles más bajos (42 ppm), las poblaciones de estas bacterias fueron más altas. Si bien el fósforo favorece la presencia de Azotobacter en el suelo, los niveles óptimos no están muy bien establecidos (Zapater, 1975; Gupta et al., 1977; Sagardoy, 1978).

El fósforo favoreció el crecimiento de los microorganismos estudiados debido a $\mathrm{su}$ rol estructural en membranas citoplasmáticas (fosfolípidos) en todos los seres vivos y por su participación en la acumulación y liberación de energía en el metabolismo celular (Alexander, 1994; Madigan, et al., 1998).

En la Tabla 1 se puede apreciar que tanto los pesos secos totales (PST) como los pesos secos del rye-grass $\mathrm{y}$ peso seco del trébol fueron mayores en el tratamiento con fósforo. Estudios realizados por diferentes investigadores demostraron que dentro de los requerimientos nutricionales de la pastura asociada rye-grass/trébol, el fósforo es un elemento importante para la productividad de la leguminosa (Langer, 1981; Skerman, 1991). 
Así mismo, el análisis de variancia reveló diferencias altamente significativas para el PST, PS rye-grass y PS trébol (Tabla 2). Estos resultados concuerdan con ensayos de fertilización fosforada en soya, donde también se encontraron diferencias significativas en el rendimiento de materia seca entre el tratamiento testigo y los tratamientos con fósforo (Lamas et al.,1997; Lamas et al., 1998).

Se percibe que el trébol respondió mejor a la fertilización con fósforo con una diferencia de 38,4\% de materia seca respecto al tratamiento sin fósforo, mientras que en la gramínea esta diferencia fue de sólo el $22,5 \%$, esto podría estar relacionado con el proceso de fijación de nitrógeno llevado a cabo por la población de rizobios, que también fueron más favorecidos por la fertilización con fósforo que la población de Azotobacter.

En el tratamiento con fósforo y durante la estación de verano (Figura 2), los más altos rendimientos de materia seca de trébol coinciden con las más altas poblaciones de rizobios del suelo y, estas poblaciones posiblemente incrementaron la nodulación del trébol que a su vez aumentaron la fijación biológica de nitrógeno lo que favoreció el crecimiento del cultivo. Esto concuerda con investigaciones de Sherwood \& Masterson (1974) que sugieren una relación entre la baja fertilidad del suelo y la baja fijación de nitrógeno. La actividad nitrogenasa también es mayor en verano y disminuye en otoño e invierno, esto debido a la diferencia de horas y cantidad de luz recibida por la leguminosa, y en consecuencia disminuye el abastecimiento de fotosintatos a los rizobios (Teklehaimanot \& Martin, 1999).

Del mismo modo, los pesos secos más altos del rye-grass corresponden a las mayores poblaciones de Azotobacter. Zúñiga y Gutiérrez-Correa (1982), observaron efectos similares en poblaciones de diazótrofos sobre plantas de Sycius baderoa, los exudados radiculares estarían ejerciendo una influencia primordial sobre los diazótrofos. Por lo tanto, Azotobacter actuaría sobre el crecimiento de las plantas al fijar $\mathrm{N}_{2}$, producir reguladores del crecimiento en la rizósfera y ser antagonista de organismos patógenos (Jackson et al., 1964).

De los análisis de correlación simple realizados entre todas las variables en el tratamiento con fósforo se encontraron algunas correlaciones significativas y altamente significativas, así tenemos que el PST presenta un $r=0.91$ con el PS rye- grass, un $r=0.5$ con la población de rizobios, un $\mathrm{r}=0.6$ con la población de hongos y un $\mathrm{r}=0.44$ con la temperatura mínima del ambiente (Tabla 3a). Mientras que en el tratamiento sin fósforo sólo se encuentra correlación significativa del PST con el PS rye-grass y el PS trébol (Tabla 3b).

En el tratamiento con fósforo no se encontró relación entre la humedad del suelo y las poblaciones microbianas estudiadas. Sin embargo, Jhoncon y Gutiérrez-Correa (1982) encontraron correlación negativa entre la población de hongos y la humedad en suelos de las Lomas de Lachay al igual que Yague y Gutiérrez- Correa (1982), para otros grupos microbianos. La humedad en este estudio, no sólo dependió de la precipitación, sino también del riego realizado por los agricultores, provocando una humedad casi constante a través del tiempo ( $40 \%$ en promedio). Tales condiciones disminuyen el espacio poroso en la solución suelo así como la aireación (Buckman y Brady, 1993; Yague y Gutiérrez- Correa, 1982). Zúñiga y Gutiérrez-Correa (1982) encontraron que la población de diazótrofos estaban influenciados positivamente por la humedad (2 - 12\%).

Al final del experimento el $\mathrm{pH}$ del suelo disminuyó de 7.5 a 6.67. A pesar de no encontrar correlación significativa entre el $\mathrm{pH}$ y las variables estudiadas, se puede apreciar una correlación negativa con el PST $(r=-0.33)$, PS rye-grass $(r=-0.39)$ y población de Azotobacter $(\mathrm{r}=-0.33)$ en el tratamiento con fósforo. Zúñiga y Gutiérrez-Correa (1982), encontraron respuesta similar entre el $\mathrm{pH}$ de la rizósfera y la población de Azotobacter. Por otro lado, no se encontró correlación del $\mathrm{pH}$ del suelo con la población de rizobios. Quigley et al. (1997) y Gibson et al. (1975), tampoco encontraron diferencias significativas entre el $\mathrm{pH}$ del suelo y la efectividad de la simbiosis leguminosa-rizobio. Es necesario estudiar la dinámica de las poblaciones microbianas en zonas altoandinas y su efecto en el crecimiento de la pastura, así como la ecología de los rizobios y el impacto de su simbiosis sobre la productividad en las pasturas, dado que, la deficiencia de la fijación de nitrógeno es la causa primaria de baja producción de materia seca de pasturas asociadas Rye-grass/trébol (Cocks, 1980).

En conclusión, la adición de fósforo mejora las condiciones del suelo y de la rizósfera, lo que a su vez favorece el crecimiento de microorganismos como hongos y bacterias y el desarrollo de las plantas.

\section{Agradecimientos}

El trabajo ha sido financiado por el proyecto ILRICIP/FAO-OIEA/SAIS Tupac Amaru / UNALM liderado po el Dr. Carlos Gómez B. de la UNALM, y por el Laboratorio de Ecología Microbiana y Biotecnología "Marino Tabusso" (Subcuenta Biología - Fundación para el Desarrollo Agrario). Agradecemos al Profesor Jesús Salinas por su colaboración en el análisis estadístico.

\section{Literatura citada}

Alexander, M. 1994. Introducción a la Microbiología de Suelos. Editor S.A. México.

Buckman H. y Brady N. 1993. Naturaleza y propiedades de los suelos. Noriega editores. España. 
Burges A. 1960. Introducción a la Microbiología de Suelos. Editorial Acribia. España.

Camarena F., Maringa A. y Chape, L. 1990. El cultivo del pallar. UNALM. Lima.

Centro Internacional de Agricultura Tropical (CIAT), 1987. Simbiosis Leguminosa - Rizobio. Manual de Métodos de Evaluación, Selección y Manejo Agronómico. Colombia.

Cocks, PS. 1980. Limitations imposed by nitrogen deficiency on the productivity of subterranean clover-based annual pasture in southern Australian. Journal of Agricultural Research. 31:95-107.

Escobedo F. 1993. Efectos de la fertilización nitrogenada en tres leguminosas forrajeras sobre la fijación de nitrógeno atmosférico determinado mediante la técnica del isótopo trazador ${ }^{15} \mathrm{~N}$. Tesis Ing. Agrónomo. UNALM.

Flores A. y Bryant F. 1989. Manual de pastos y forrajes. Programa colaborativo de Apoyo a la Investigación en Rumiantes menores. Lima - Perú.

Flores, A. y Malpartida, E. 1987. Manejo de praderas nativas de la región altoandina del Perú. Tomo II. Banco Agrario. Lima - Perú.

Gavande S. 1979. Física de suelos principios y aplicaciones. Editorial Limusa. México.

Gibson A.H., Curnow B.C., Bergensen F.J., Brockwell J., Ald Robinson A.C. 1975. Studies of field satrains of Rhizobium trifolli asociated with Trifolium subterraneum L. pastures in southeastern Australian. Soil Biology and Chemistry. 7: $95-102$.

Gupta R.D., Jha D.D., Sothi A. \& Saharan, G.S. 1977. Presence of Azotobacter in relation to physicochemical properties of some North Indian soils. Proc. Indian Acad. Science. 86: 389 - 395.

Gutiérrez-Correa M. y Jhoncon J. 1982. Ecología de Penicillium en los suelos de las Lomas de Lachay (Perú).I.-Dinámica poblacional. Zonas Aridas $\mathrm{N}^{\circ} 2: 87-91$.

Jackson R.M., Margaret B., Burlingham S.D. 1964. Similar effects on tomato plants of Azotobacter inoculation and application of giberellina. Nature. 203: $851-852$

Jhoncon J. y Gutiérrez-Correa M. 1983. Ecología de Penicillium en los suelos de las Lomas de Lachay. Zonas Aridas. No 3:91-94

Krieg N.R. \& Dobereiner J. 1984. Genus Azospirillum. pp. 94-103. In:Bergey's Manual of Systematic Bacteriology, vol. I. N.R. Krieg y J.G Holt(eds.). The Williams \& Wilkins Co. Baltimore.

Langer R.H.M. 1981. Las pasturas y sus plantas. Editorial Hemisferio Sur. Uruguay.

Lamas M., Prieto G., Bodrero M., Udaquiola S. y Lotano J. 1997. Resultados preliminares de ensayos de fertilización fodforada en soya (Glycine max (L.) Merr.), realizados en el sur de
Santa Fe. Rev. Facultad de Agronomía. 17 (3): 297-303.

Lamas M., Prieto G. y Ras, C. 1998. Estado nutricional del cultivo de soya en suelos con distintos niveles de fósforo en el sur de Santa Fé. Rev. Fac. Agronomía. 17(3): 304 - 309.

Madigan M., Martinko, J., Parker, J. 1997. Brock Biología de los Microorganismos. Octava Edición. Prentice Hall.

Matos-Cuzcano G., Ormeño E. y Zúñiga D. 1998. Diversidad de los Rhizobios que nodulan el cultivo del pallar (Phaseolus lunatus L.) en la costa central del Perú. Ecología. 1(1): 42-46.

Merck, 1994. Manual de Medios de Cultivo. E. Merck, Darmstadt, Alemania.

Ministerio de Agricultura. 1994. III Censo Nacional. http//: minag.gob.pe

Oficina Nacional de Evaluación de Recursos Naturales (ONERN) 1976. Inventario y evaluación de los Recursos Naturales de la Sais Tupac Amaru . Ministerio de Agricultura. Lima.

Quigley P.E. Cunningham P.J., Hannah M., Ward G.N. \& Morgan T. 1997. Symbiotic effectiveness of Rhizobium leguminosarum bv. trifolii collected from pastures in south-western Victoria. Australian Journal of Experimental Agriculture. 37: $623-630$

Sagardoy M.A. 1978. Dinámica de la microflora en un suelo cultivado con ajo (Allium sativum L.) Rev. Ecol. Biol. Soil. 15: 191-204.

Sherwood M.T. \& Masterson C.L. 1974. Importance of using the correct test host in assessing the effectiveness of indigenous populations of Rhizobium trifolii. Irish Journal of Agricultural reserch. 13: $101-108$.

Skerman P.J. 1991. Leguminosas forrajeras tropicales. Colección FAO Producción y Protección Vegetal $\mathrm{N}^{\circ} 2$.

Somasegaran P. \& Hoben H.J. 1985. Methods in Legume-Rhizobium Technology. Niftal Project and MIRCEN. Hawaii.

Sylvia D.M., Fuhrmann J., Hartel P.G. \& Zuberer D. 1998. Principles and Aplications of Soil Microbiology. Prentice-Hall, Inc. New Jersey.

Teklehaimanot Z. \& Martin R. 1999. Diurnal and seasonal patterns of nitrogenase activity of red alder in comparison with white clover in silvopastoral agroforestry systems. Biol. Fertil Soils. 28: 267-270.

Universidad Nacional Agraria La Molina (UNALM). 1998. Manual de Edafología. Facultad de Agronomía. Departamento de Suelos Lima - Perú.

Vigo M.J. 1971. Valor nutritivo del Rye -grass ( $L$. perenne) y trébol blanco (T. repens) en pasturas asociadas en Cajamarca. Tesis Ing. Zootecnista. UNALM 
Yague N. y Gutiérrez-Correa M.1982. Bacterias en el ciclo del nitrógeno en suelos de las Lomas de Lachay. Zonas Aridas. No 1: 75-80.

Zapater J.M. 1975. Evaluación en el maíz del coeficiente rizósfera-suelo $(\mathrm{R} / \mathrm{S})$ referidos a bacterias libres fijadoras de nitrógeno. Anales científicos UNA. 13: 45 - 57.
Zúñiga D. y Gutiérrez-Correa M. 1982. Diazótrofos libres en la rizósfera de Sicyos baderoa Lomas de Lachay. Lima, Perú. Zonas Aridas. No 2: 79-86

Zúñiga D. 1997. Contribución relativa de los simbiontes en la fijación de nitrógeno para Phaseolus vulgaris en condiciones de estrés salino. Tesis Doctoral. Granada, España.

Anexos: figuras y tablas citadas en el texto.

Fig. No. 1 Variación temporal de la Población Microbiana (Enero 99 a Dic - 99)

1a.Variación de la población de bacterias mesófilas

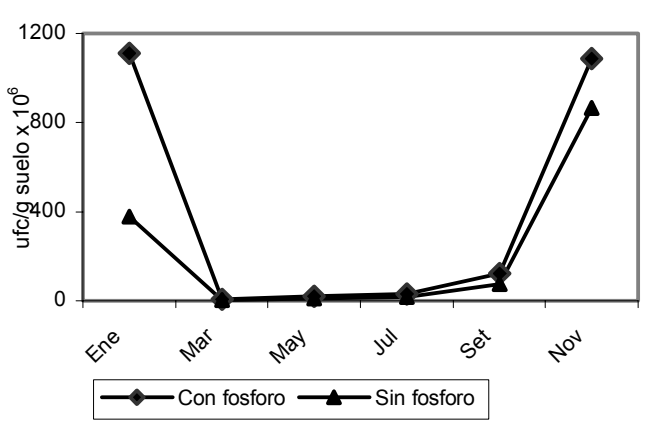

1c. Variacion de la población de Rhizobium

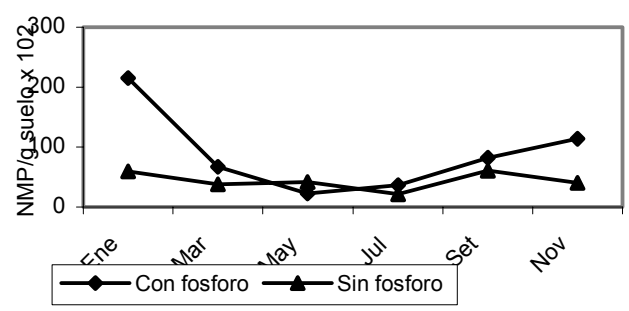

1b. Variación de la población de hongos totales

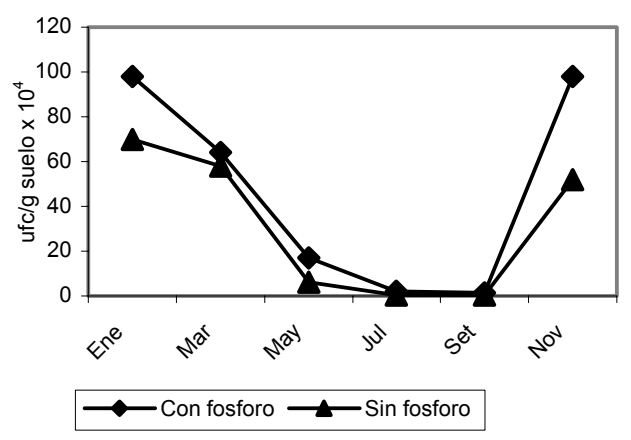

1d. Variación de la poblacion de Azotobacter

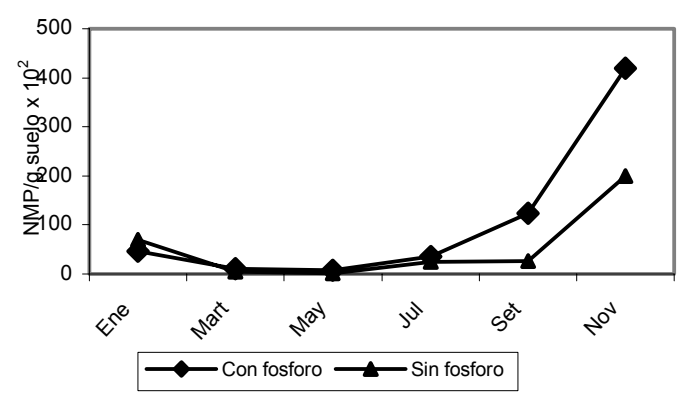


Fig. No.2 Datos Meteorológicos de Temperatura y Precicpitación Ambiental (Jul-98 a Dic-99)

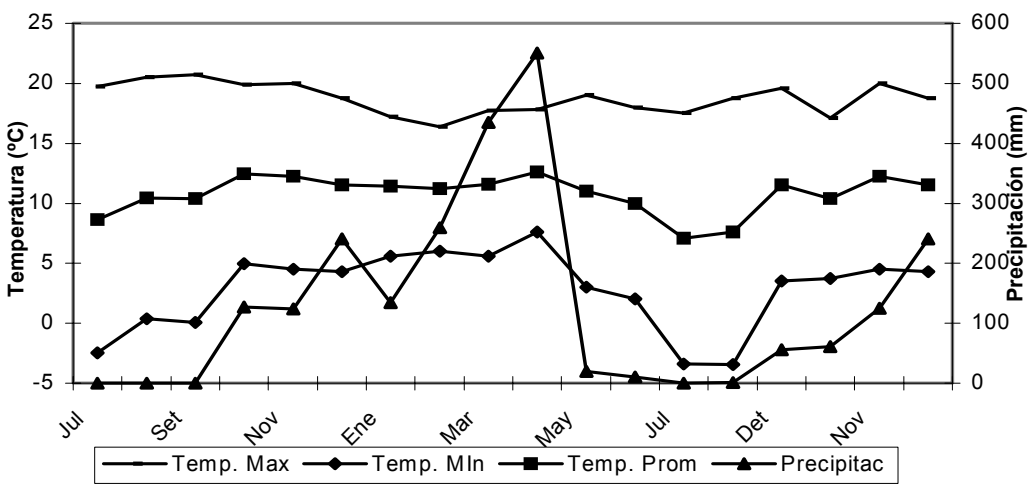

Fig. No.3 Datos de Temperatura. pH y Humedad del suelo (Jul-98 a Dic-99)

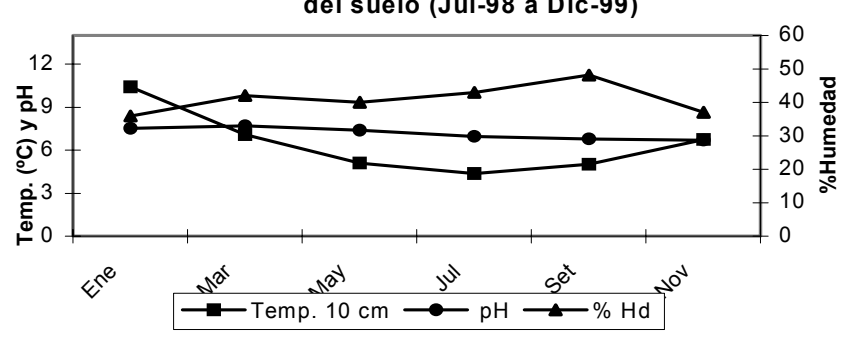

Tabla 1. Efecto del fósforo sobre el peso seco del follaje

\begin{tabular}{|c|c|c|c|c|}
\hline Muestreo & $\begin{array}{c}\text { Tratamien } \\
\text { to }\end{array}$ & PST & $\begin{array}{c}\text { PS Rye- } \\
\text { grass }\end{array}$ & PS Trébol \\
\hline \multirow{2}{*}{ Enero-99 } & $+\mathrm{P}$ & 105 & 77.7 & 27 \\
\cline { 2 - 5 } & $-\mathrm{P}$ & 84 & 70 & 14 \\
\hline \multirow{2}{*}{ Marzo-99 } & $+\mathrm{P}$ & 90 & 77 & 13.5 \\
\cline { 2 - 5 } & $-\mathrm{P}$ & 80 & 72 & 8 \\
\hline \multirow{2}{*}{ Mayo-99 } & $+\mathrm{P}$ & 86 & 74.75 & 11.25 \\
\cline { 2 - 5 } & $-\mathrm{P}$ & 77.01 & 68 & 9.25 \\
\hline \multirow{2}{*}{ Julio-99 } & $+\mathrm{P}$ & 65.5 & 61.5 & 4 \\
\cline { 2 - 5 } & $-\mathrm{P}$ & 63.5 & 57 & 6.51 \\
\hline \multirow{2}{*}{ Setiembre-99 } & $+\mathrm{P}$ & 66.76 & 62.5 & 4.26 \\
\cline { 2 - 5 } & $-\mathrm{P}$ & 63.31 & 60.25 & 3.06 \\
\hline \multirow{2}{*}{ Noviembre-99 } & $+\mathrm{P}$ & 116 & 105.25 & 10.75 \\
\cline { 2 - 5 } & $-\mathrm{P}$ & 81.25 & 74.75 & 6.5 \\
\cline { 2 - 5 } & $\mathrm{DLS}$ & 7.7287 & 7.0576 & 4.988 \\
\hline
\end{tabular}

\begin{tabular}{|} 
Tabla 2. Análisis de Variancia del peso seco total, del Rye Grass y Trébol. \\
\hline \multicolumn{7}{|c|}{ Variable dependiente: Peso seco total } \\
\hline Source & DF & Anova SS & $\begin{array}{c}\text { Mean } \\
\text { Square }\end{array}$ & F Value & Pr $>$ F \\
\hline Bloque & 3 & 18413.54 & 6137.84 & 10.88 & $0.0003^{*}$ \\
\hline Tiempo & 5 & 61195.16 & 12239.0326 & 21.69 & $0.0001^{*}$ \\
\hline Bloque*Tiempo & 15 & 8271.13 & 551.4 & 0.98 & 0.5124 \\
\hline Tratamiento & 1 & 25784.09 & 25784.0926 & 45.69 & $0.0001^{*}$ \\
\hline Tiempo*tto & 5 & 43589.12 & 8717.82 & 24.58 & $0.0001^{*}$
\end{tabular}


Diciembre 2002

\section{EFECTO DEL FOSFORO SOBRE LA POBLACION MICROBIANA EN SUELOS}

Continuación Tabla 2...

\begin{tabular}{|c|c|c|c|c|c|}
\hline \multicolumn{7}{|c|}{18} & 10158.64 & 564.368854 & 1.59 & 0.1009 \\
\hline Bloque*tto(tiempo) & \multicolumn{7}{c|}{ Variable dependiente: Peso seco Rye Grass } \\
\hline Bloque & 3 & 8370.79 & 2790.26 & 6.01 & $0.0051^{*}$ \\
\hline Tiempo & 5 & 21446.71 & 4289.34 & 9.24 & $0.0002^{*}$ \\
\hline Bloque*Tiempo & 15 & 6440.46 & 429.36 & 0.93 & 0.5554 \\
\hline Tratamiento & 1 & 9087.04 & 9087.04 & 19.58 & $0.0003^{*}$ \\
\hline Tiempo*tto & 5 & 12935.71 & 2587.14 & 8.75 & $0.0001^{*}$ \\
\hline Bloque*tto(tiempo) & 18 & 8352.25 & 464.01 & 1.57 & 0.1078 \\
\hline \multicolumn{7}{|c|}{ Variable dependiente: Peso seco Trébol } \\
\hline Bloque & 3 & 2375.69 & 791.9 & 8.43 & $0.001^{*}$ \\
\hline Tiempo & 5 & 11692.23 & 2338.45 & 24.9 & $0.0001^{*}$ \\
\hline Bloque*Tiempo & 15 & 2828.88 & 188.59 & 2.01 & 0.0801 \\
\hline Tratamiento & 1 & 3766.27 & 3766.27 & 40.1 & $0.0001^{*}$ \\
\hline Tiempo*tto & 5 & 8535.09 & 1707.02 & 11.56 & $0.0001^{*}$ \\
\hline Bloque*tto(tiempo) & 18 & 1690.69 & 93.93 & 0.64 & 0.8526 \\
\hline
\end{tabular}

$* \alpha=0.05$

Tabla 3a. Matriz de Correlación de los factores en estudio del tratamiento con Fósforo.

\begin{tabular}{|c|c|c|c|c|c|c|c|c|c|c|c|c|c|c|}
\hline & PST & PS rg & PS t & RHZ & AZT & BACT & $\begin{array}{c}\text { HON } \\
\text { G }\end{array}$ & $T^{0} S$ & $\% \mathrm{Hd}$ & $\mathbf{p H}$ & $\mathbf{T}^{0} \mathrm{Max}$ Amb & $\begin{array}{c}\mathbf{T}^{0} \text { Min } \\
\text { Amb }\end{array}$ & $\mathrm{T}^{0}$ Prom & $\mathbf{P P}$ \\
\hline PST & 1.00 & & & & & & & & & & \multirow{3}{*}{\multicolumn{4}{|c|}{ V.C $n=24$}} \\
\hline PS Rye-grass & 0.91 & 1.00 & & & & & & & & & & & & \\
\hline PS trebol & 0.35 & 0.15 & 1.00 & & & & & & & & & & & \\
\hline Rhizobium *102 & 0.50 & 0.21 & 0.11 & 1.00 & & & & & & & $P \leq 0.05$ & $\mathrm{P} \leq 0.01$ & $P \leq 0.001$ & \\
\hline $\begin{array}{l}\text { Azotobacter } \\
* 102\end{array}$ & 0.29 & 0.51 & -0.30 & -0.01 & 1.00 & & & & & & 0.404 & 0.515 & 0.628 & \\
\hline Bacterias *105 & 0.37 & 0.35 & -0.12 & 0.48 & 0.41 & 1.00 & & & & & & & & \\
\hline Hongos *104 & 0.60 & 0.50 & 0.04 & 0.59 & 0.41 & 0.59 & 1.00 & & & & & & & \\
\hline$T^{0}$ suelo $10 \mathrm{~cm}$ & 0.33 & 0.19 & 0.44 & 0.39 & 0.02 & 0.37 & 0.65 & 1.00 & & & & & & \\
\hline$\%$ Hd suelo & -0.08 & 0.01 & -0.16 & -0.05 & 0.10 & -0.37 & -0.19 & -0.21 & 1.00 & & & & & \\
\hline pH suelo & -0.33 & -0.39 & -0.09 & -0.17 & -0.33 & -0.09 & 0.11 & 0.26 & -0.26 & 1.00 & & & & \\
\hline $\mathbf{T}^{0} \mathbf{M a x}$ Amb & 0.09 & 0.29 & 0.03 & -0.17 & 0.53 & 0.17 & -0.16 & -0.18 & 0.12 & -0.68 & 1.00 & & & \\
\hline $\mathbf{T}^{0}$ Min Amb & 0.44 & 0.34 & 0.19 & 0.40 & 0.15 & 0.38 & 0.58 & 0.69 & -0.08 & 0.05 & 0.19 & 1.00 & & \\
\hline Temp. Prom & 0.42 & 0.40 & 0.18 & 0.31 & 0.30 & 0.40 & 0.47 & 0.56 & -0.03 & -0.17 & 0.48 & 0.95 & 1.00 & \\
\hline Precipitación & 0.22 & 0.17 & -0.17 & 0.11 & -0.07 & -0.03 & 0.38 & 0.31 & -0.03 & 0.43 & -0.28 & 0.59 & 0.44 & 1.00 \\
\hline
\end{tabular}

Tabla 3b. Matriz de Correlación de los factores en estudio del tratamiento sin Fósforo.

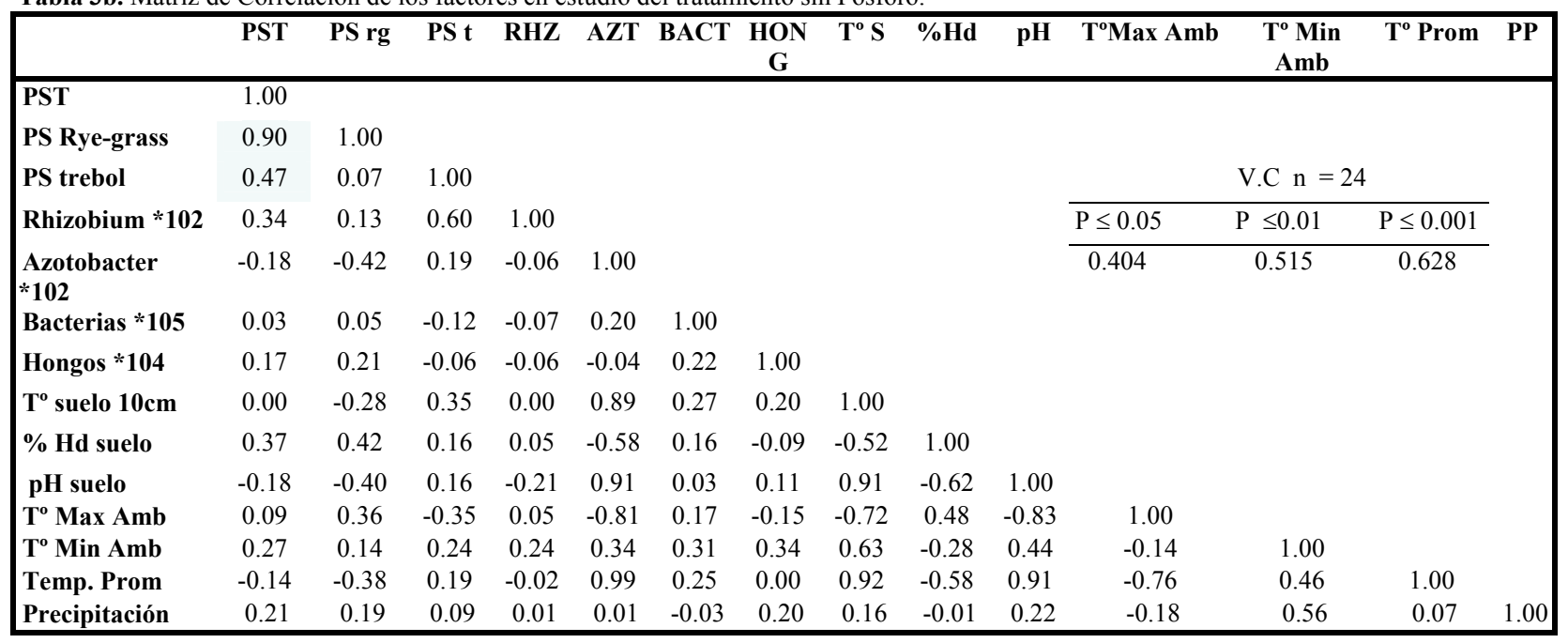

